\title{
Ekstrak Antosianin Dari Ubi Ungu (Ipomoea Batatas L.) Sebagai Pewarna Alami Pada Pemeriksaan Soil Transmitted Helminths (STH) Metode Natif (Direct Slide)
}

\author{
${ }^{1}$ Subakir Salnus \\ ${ }^{2}$ Dzikra Arwie \\ ${ }^{3}$ Zulfian Armah
}

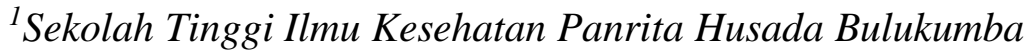

${ }^{2}$ Sekolah Tinggi Ilmu Kesehatan Panrita Husada Bulukumba

${ }^{3}$ Politeknik Kesehatan Kementerian Kesehatan Makassar
}

\begin{abstract}
Alamat Korespondensi:
Zulfian Armah

Teknologi Laboratorium Medik

Politeknik Kesehatan Kementerian Kesehatan Makassar

O82393644353

Email: akil.ladzinrank@gmail.com
\end{abstract}




\begin{abstract}
ABSTRAK
Helminthiasis atau kecacingan merupakan infestasi cacing yang disebabkan oleh beberapa spesies cacing parasit usus yang berbeda. Kelompok cacing ini termasuk kategori Soil Transmitted Helminth (STH) karena proses perkembangan telur atau larva dari spesies tersebut memerlukan tanah untuk berkembang menjadi bentuk yang infektif. Teknik pemeriksaan telur cacing Nematoda Usus yang paling sederhana adalah Metode Natif menggunakan reagen Eosin 2\% dalam mengamati berbagai unsur pemeriksaan pada preparat/sediaan. Eosin sendiri memiliki sifat tidak mudah terurai, dan menimbulkan limbah yang berbahaya (toxic) serta mudah terbakar (flammable) sehingga diperlukan pewarnaan alternatif pengganti yang bersifat lebih ramah lingkungan. Ubi jalar ungu memiliki kandungan pigmen antosianin yang tinggi dan lebih stabil daripada pigmen stroberi, kubis merah, perilla dan tumbuhan lainnya. Dengan demikian, ubi jalar ungu telah dianggap sebagai sumber antosianin yang baik. Penelitian ini bertujuan untuk mengetahui penggunaan ekstrak antosianin dari ubi ungu sebagai pewarna alami pengganti pewarna eosin pada identifikasi STH metode natif. Parameter yang diamati pada sediaan/preparat yaitu kualitas kontras lapang pandang, daya serap warna pada permukaan parasit, serta tingkat kejelasan penampakan parasit. Hasil penelitian menunjukkan penggunaan ekstrak antosianin dari ubi ungu pada konsentrasi $80 \%$ dapat mewarnai telur cacing STH yang di temukan pada sampel positif jenis ascaris lumbricoides terlihat dalam bentuk fertil (telur yang di buahi) dan infertil (telur yang tidak di buahi). Oleh karena itu, ekstrak antosianin yang diperoleh dari ubi ungu memiliki potensi sebagai pewarna alternatif pengganti eosin.
\end{abstract}

\title{
Kata Kunci: Ekstrak antosianin, Ubi ungu, Soil Transmitted Helminth
}

\begin{abstract}
Helminthiasis is a worm infestation caused by several different species of intestinal parasitic worms. This group of worms belongs to the category of Soil Transmitted Helminth (STH) because the process of developing eggs or larvae of these species requires soil to develop into an infective form. The simplest method of examining intestinal nematode worm eggs is the Native Method using 2\% Eosin reagent in observing various elements of the examination on the preparations/preparations. Eosin itself has properties that are not easily biodegradable, and generates hazardous waste (toxic) and flammable so that alternative coloring is needed that is more environmentally friendly. Purple sweet potato has a high content of anthocyanin pigments and is more stable than the pigments of strawberries, red cabbage, perilla and other plants. Thus, purple sweet potato has been considered a good source of anthocyanins. This study aims to determine the use of anthocyanin extract from purple sweet potato as a natural dye substitute for eosin dye in the identification of STH in the native method. Parameters observed in the preparations were the quality of visual field contrast, color absorption on the surface of the parasite, and the level of clarity of the appearance of the parasite. The results showed that the use of anthocyanin extract from purple sweet potato at a concentration of $80 \%$ could color the eggs of STH worms which were found in positive samples of Ascaris lumbricoides seen in fertile (fertilized eggs) and infertile (unfertilized eggs). Therefore, the anthocyanin extract obtained from purple sweet potato has potential as an alternative dye to replace eosin.
\end{abstract}

\section{Keyword: Anthocyanin, Purple sweet potato, Soil Transmitted Helminth}




\section{PENDAHULUAN}

Kecacingan merupakan penyakit infeksi yang umum terjadi di daerah tropis dan sub tropis. Tahun 2015, World Health Organization (WHO) menyebutkan bahwa sebanyak $24 \%$ populasi di dunia mengalami kecacingan. Sub-Sahara Afrika, Amerika, Cina, dan Asia Timur memiliki angka kejadian terbesar Penyakit kecacingan di Indonesia memiliki prevalensi sebesar 45\%$65 \%$. Infeksi kecacingan banyak di temukan di daerah yang memiliki sanitasi dan higienitas yang buruk, air yang terkontaminasi, lingkungan yang padat penduduk, serta cuaca yang panas dan lembab Kecacingan dalam dampak panjang berisiko menyebabkan defisiensi gizi yang dapat mengakibatkan status gizi yang buruk, pertumbuhan terhambat hingga menurunnya kemampuan kognitif (Putri dkk., 2019).

Prevalensi infeksi cacing di Indonesia masih tergolong tinggi terutama pada penduduk miskin dan hidup di lingkungan padat penghuni dengan sanitasi yang buruk, tidak mempunyai jamban dan fasilitas air bersih tidak mencukupi. Hasil survei Departemen Kesehatan Republik Indonesia di beberapa provinsi di Indonesia menunjukkan prevalensi kecacingan untuk semua umur di Indonesia berkisar antara 40\%-60\%. Sedangkan prevalensi kecacingan pada anak di seluruh Indonesia pada usia 1-6 tahun atau usia 7-12 tahun berada pada tingkat yang tinggi, yakni $30 \%$ hingga 90\% (Rosyidah dkk., 2018).

Teknik pemeriksaan telur cacing Nematoda Usus yang paling sederhana adalah Metode Natif, Teknik ini menggunakan reagen Eosin 2\% dengan tujuan antara lain untuk menilai berbagai unsur dalam sediaan/preparat. Eosin sendiri memiliki sifat tidak mudah terurai, dan menimbulkan limbah yang berbahaya (toxic) serta mudah terbakar (flameable). Di era global saat ini, kesadaran masyarakat terhadap bahan bersifat organik dan berasal dari alam yang ramah lingkungan (ecofriendly) lebih tinggi, sehingga diperlukan alternatif metode pewarnaan menggunakan bahan alami, seperti dengan pemanfaatan zat pewarna alami antosianin yang berasal dari ekstrak ubi ungu.

Senyawa antosianin merupakan senyawa polifenol alam yang terkandung dalam buah-buahan, kacang-kacangan, sereal dan sayuran menyebabkan warna merah, biru dan ungu. Antosianin dianggap sebagai senyawa metabolit sekunder golongan flavonoid karena karakteristik struktur kerangka karbon C6C3C6 yang dimilikinya. Pigmen warna yang ditimbulkan oleh kelompok senyawa 
antosianin bergantung pada substituen di cincin A dan cincin B (Singh dkk., 2020).

Antosianin akan memberikan perubahan warna pada $\mathrm{pH}$ tertentu, seperti $\mathrm{pH}$ untuk masing-masing jenis leukosit, sehingga dengan pewarnaan antosianin dapat memberikan warna yang berbeda untuk setiap jenis sel. Penelitian sebelumnya yang berjudul optimasi rendaman batang pohon jati (Tectona grandis) dalam pemeriksaan STH menyatakan bahwa tidak ada perbedaan yang nyata antara perlakuan pewarnaan menggunakan rendaman batang pohon jati dengan eosin 2\% (Sari dkk., 2019).

Ubi jalar ungu memiliki kandungan pigmen antosianin yang tinggi dan lebih stabil daripada pigmen stroberi, kubis merah, perilla dan tumbuhan lainnya. Dengan demikian, ubi jalar ungu telah dianggap sebagai sumber antosianin yang baik.

\section{METODE}

Jenis penelitian yang digunakan adalah penelitian deskriptif, yaitu gambaran STH pada pemeriksaan sampel feses menggunakan pewarnaan ekstrak antosianin berbagai variasi dan pewarna eosin. Senyawa antosianin pada ubi ungu terlebih dahulu diekstraksi menggunakan pelarut etanol-HCl yang bersifat asam $(\mathrm{pH} 4)$ agar kondisi senyawa antosianin tetap dalam keadaan stabil. Ekstrak yang diperoleh lalu dipekatkan melalui proses evaporasi (penguapan) pelarut sehingga diperoleh ekstrak kental bebas pelarut dan dianggap sebagai konsentrasi 100\%. Tahap selanjutnya yaitu membuat variasi ekstrak antosianin untuk dijadikan sebagai pewarna menggunakan pelarut akuades sehingga akan diperoleh pewarnaan yang optimum pada konsentrasi tertentu. Penentuan konsentrasi ekstrak antosianin dihitung menggunakan rumus pengenceran:

$\%$ Konsentrasi $=\frac{\text { volume ekstrak antosianin terlarut }}{\text { volume akuades yang ditambahkan }} \times 100 \%$

Metode pemeriksaan STH yang digunakan adalah pemeriksaan secara natif (langsung) dimana sampel feses yang positif mengandung STH diperiksa dengan cara meneteskan larutan eosin 1-2 tetes pada object glass. Kemudian diambil feses seujung lidi dan diaduk hingga rata dengan larutan eosin pada object glass. Lalu ditutup dengan dect glass dan dilakukan pengamatan dengan menggunakan mikroskop pembesaran 10x10. Kemudian dilanjutkan dengan perbesaran 10x40. Jika ditemukan telur cacing nematoda usus antara lain telur cacing Ascaris lumbricoides, Trichuris trichiura, Necator americanus maka dinyatakan positif kecacingan. Hal yang sama dilakukan terhadap pewarnaan 
ekstrak antosianin dari berbagai variasi konsentrasi.

\section{HASIL}

Ekstrak antosianin yang diperoleh dari ubi ungu menunjukkan hasil yang lebih jelas dibawah pengamatan mikroskop pada konsentrasi 80\%. Pada Gambar 1. merupakan gambaran beberapa telur cacing STH yang di temukan di dalam spesimen feses responden dengan jenis parasit yaitu Ascaris lumbricoides. Untuk gambar (a) dan (b) merupakan gambar kontrol positif telur cacing STH jenis Ascaris lumbricoides yang dibuahi (fertil) dan telur yang tidak di buahi (infertil). Adapun pada gambar (c) adalah salah satu gambar telur cacing STH yang di temukan pada salah satu sampel responden dengan jenis parasit Ascaris lumbricoides dalam bentuk fertil sedangkan pada gambar (d) adalah gambar telur cacing ascaris lumbricoides dalam bentuk infertil.

\section{PEMBAHASAN}

Proses ekstraksi antosianin dilakukan dengan cara merendam ubi ungu yang telah diparut sebelumnya kedalam pelarut etanol$\mathrm{HCl}$ ( $\mathrm{pH}$ 4) dengan tujuan senyawa antosianin akan lebih stabil pada suasana pelarut yang asam. Pada penelitian ini, ekstrak antosianin yang lebih bagus menunjukkan gambaran telur STH yang baik berdasarkan parameter pengamatan dibawah mikroskop adalah ekstrak antosianin pada konsentrasi 80\%. Adapun gambar yang ditunjukkan dari hasil pengamatan diketahui bahwa jenis parasit STH pada spesimen feses responden adalah Ascaris lumbricoides. Adapun bentuk telur STH tersebut yaitu fertil dan infertil. Pada telur fertil memiliki ciri-ciri selaput kulit telur yang tidak terwarnai, berlapis dan berbentuk oval, sedangkan telur infertil memiliki ciriciri kulit telur yang terwarnai tidak memiliki lapisan selaput dan bentuk yang agak lonjong dengan ukuran yang lebih besar.

\section{KESIMPULAN DAN SARAN}

Sebagai kesimpulan, ekstrak antosianin dari ubi ungu dapat dijadikan sebagai pewarna alternatif untuk pemeriksaan parasit soil transmitted helminth (STH) metode natif. Adapun saran, penggunaan ekstrak antosianin dari sumber lain selain ubi ungu dapat dilakukan.

\section{DAFTAR PUSTAKA (REFERENSI)}

P. Puteri, P., Nuryanto, N., Candra, A. 2019. Hubungan Kejadian Kecacingan Terhadap Anemia Dan Kemampuan Kongnitif Pada Anak Sekolah Dasar di kelurahan Bandarhorjo, Semarang. Journal of Nutrition College, 8(2): 101-106.

Rosyidah, H. N., Prasetyo, H. 2018. Prevalence of intestinal helminthiasis 
in children at north keputran surabaya at 2017. Journal of Vocational Health Studies, 1: 117-120.

Salnus, S., Arwie, D. 2020. Ekstrak antosianin dari ubi ungu (Ipomoea batatas L.) sebagai pewarna alami pada sediaan apusan darah tepi. Jurnal Media Analis Kesehatan, 11(2): 96103. Doi: 10.32382/mak.v11i2.1771.

Sari, Y. E. S., Artanti, D., Rozi, F. 2019. Optimasi rendaman batang pohon jati (tectona grandis) dalam pemeriksaan soil transmitted helminth. Teklabmed Jurnal Teknologi Laboratorium Medis, 1(1): 1-6.

Singh, M.C., Kelso, C., Price, W.E., Probst, Y. 2020. Validated liquit chromatography separation methods for identification and quantification of anthocyanins in fruit and vegetables: a systematic review. Food Research International, 138(A): 109754. 


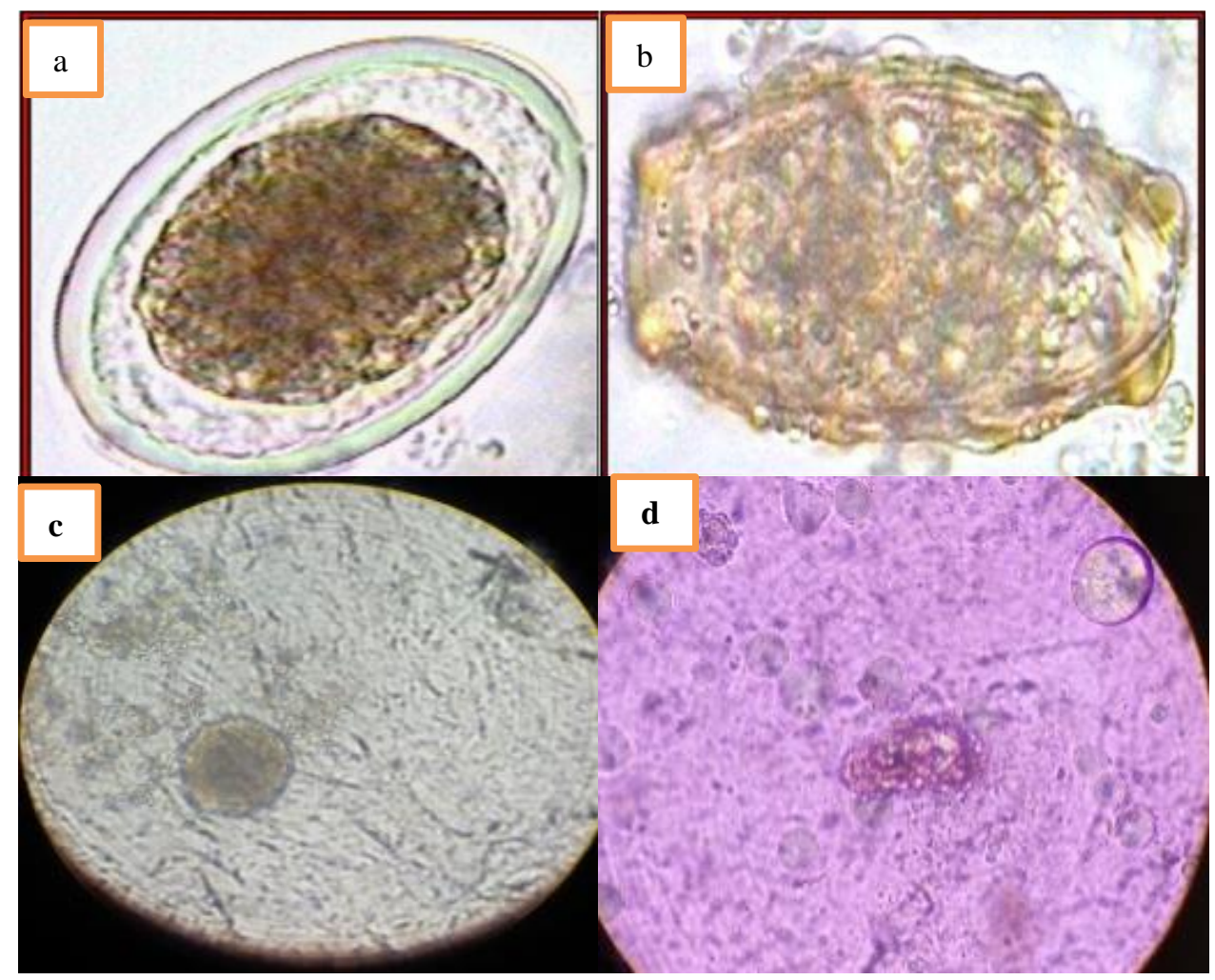

Gambar 1. Telur cacing Ascaris Lumbricoides 